\title{
Changes in haematological parameters and iron metabolism associated with a 1600 kilometre ultramarathon
}

\author{
K E Fallon, G Sivyer, K Sivyer, A Dare
}

\begin{abstract}
Objective-To investigate haematological variations and iron related changes in the serum of participants in a 1600 kilometre ultramarathon run.

Participants-Seven male and two female participants in a $1600 \mathrm{~km}$ foot race.

Methods-Blood samples were obtained from the participants before, after four and 11 days of running, and at the end of the event. Samples were analysed by standard methods for haemoglobin, packed cell volume, total red cell count, mean red cell volume, mean red cell haemoglobin, total white cell count and differential, platelets, reticulocytes, iron, ferritin, total iron binding capacity, percentage transferrin saturation, haptoglobin, and bilirubin and corrected for changes in plasma volume.
\end{abstract}

Results-The following variables decreased during the event $(p<0.05)$ : haemoglobin, packed cell volume, mean red cell volume, percentage lymphocytes, percentage monocytes, serum iron, total iron binding capacity, and percentage transferrin saturation. Increases $(p<0.05)$ were found in plasma volume, total red cell count (day 4 only), total white cell count, percentage and absolute numbers of neutrophils and reticulocytes, absolute numbers of lymphocytes and monocytes (day 4 only), absolute numbers of eosinophils (day 11 and race end), absolute numbers of basophils (race end only), platelets, ferritin, haptoglobin, and bilirubin (day 4 only).

Conclusion-Ultramarathon running is associated with a wide range of changes in haematological parameters, many of which are related to the normal acute phase response to injury. These should not be confused with indicators of disease. (Br f Sports Med 1999;33:27-32)

Keywords: ultramarathon; haematology; iron; haemolysis; plasma volume

The marathon and ultramarathon events, generally those up to 24 hours' duration, have been subjected to intense study. Little has been reported about the biochemical and haematological changes occurring during and after long ultramarathons. In the only study of haematological parameters in an event of $1000 \mathrm{~km}$ or longer the event was a staged race in which the participants covered only $50 \mathrm{~km}$ a day and had long periods of rest. ${ }^{1}$ In addition, previous studies have failed to correct findings for changes in plasma volume, which may be of the order of $10-20 \%$. This paper describes haematological parameters and those related to iron metabolism and haemolysis in an event in which only short sleep breaks were taken, and these variables were individually corrected for changes in plasma volume.

\section{Methods}

Before the start of this study approval was obtained from the ethics committee of the South Queensland Regional Health Authority. All procedures conformed to the National Health and Medical Research Council guidelines for experimentation with human subjects, and all subjects gave their informed written consent before participation in this study.

Seven male and two female experienced ultramarathon runners participating in the $1600 \mathrm{~km}$ ultramarathon in Nanango, Australia volunteered for this study. The data of those who completed at least $1000 \mathrm{~km}$ were included in the analysis. The ultramarathon was a continuous event, the object being to cover $1600 \mathrm{~km}$ (1000 miles) in the shortest possible time. Runners competed on a $400 \mathrm{~m}$ oval grass track, the surface of which changed progressively to dirt after the first three days of the event. Temperature range during the 16 days of the event was $11.0-31.8^{\circ} \mathrm{C}$ and the relative humidity $17-100 \%$. The runners were allowed free intake of their usual diets during the study period. A medical and training history was obtained before the race started.

Four runners completed $1600 \mathrm{~km}$ in less than 16 days, three completed 16 days of running but did not complete $1600 \mathrm{~km}$, and two completed shorter distances $(1364 \mathrm{~km}$ and $1044 \mathrm{~km}$ ) in less than 16 days.

Twenty five millilitres of blood was drawn from an antecubital vein, using sterile technique, about 30 minutes before the start. Further samples were obtained between 9 and 10 am on days 4 and 11 and at the end of the run. The mean delay in sampling after the event was less than 30 minutes. Each sample was obtained with the subject in the seated position. All specimens were transported to the laboratory within one hour of venepuncture.

Full blood counts were performed on a Coulter Stack "C" autoanalyser. Serum iron concentration was measured by ascorbic acid reduction on a Boehringer MannheimHitachi 917 analyser. Total iron binding capacity was calculated from serum transferrin 
Table 1 Subject characteristics

\begin{tabular}{llll}
\hline Parameter & Mean & Standard deviation & Range \\
\hline Age & 53 & 11.2 & $41-76$ \\
Training distance $(\mathrm{km} / \mathrm{wk})$ & 194 & 212 & $50-650$ \\
Years of running & 20 & 12 & $6-40$ \\
Previous ultramarathons & 34 & 34 & $6-100$ \\
Previous marathons & 19 & 17 & $1-50$ \\
Best marathon time $(\mathrm{h})$ & 3.26 & 0.55 & $2.5-4.3$ \\
\hline
\end{tabular}

Table 2 Performance data

\begin{tabular}{llllll}
\hline Runner & Time (days) & Distance $(\mathrm{km})$ & Rate $(\mathrm{km} /$ day) & Day 4 $(\mathrm{km})$ & Day 11 $(\mathrm{km})$ \\
\hline $\mathrm{A}$ & 11.45 & 1600 & 139.7 & 490.2 & 1306.5 \\
$\mathrm{~B}$ & 11.79 & 1600 & 135.7 & 520.8 & 1317.8 \\
$\mathrm{C}$ & 14.44 & 1600 & 110.8 & 520.4 & 1249.4 \\
$\mathrm{D}$ & 14.95 & 1600 & 107.8 & 498.7 & 1231.7 \\
$\mathrm{E}$ & 11.49 & 1364 & 118.7 & 545.4 & 1308.9 \\
$\mathrm{~F}$ & 16 & 1346 & 84.1 & 409.3 & 1019.5 \\
$\mathrm{G}$ & 16 & 1146 & 71.6 & 297 & 785.3 \\
$\mathrm{H}$ & 16 & 1138 & 71.1 & 327 & 802.6 \\
I & 14.89 & 1044 & 70.1 & 329.6 & 782.9 \\
Mean & 14.11 & 1382 & 96.7 & 437.6 & 1089.4 \\
SD & 1.98 & 229 & 21.7 & 97.7 & 241.6 \\
\hline
\end{tabular}

concentration, measured by immunoturbidimetry on a Boehringer Mannheim-Hitachi 917 analyser. Transferrin saturation was calculated from the formula: (serum iron/total iron binding capacity) $\times 100$. Ferritin concentration was analysed by immunoassay performed by automated chemiluminescence on a Ciba-Corning ACS 180 analyser. Serum haptoglobin concentration was measured by immunoturbidimetry on a Boehringer Mannheim-Hitachi 917 analyser. Estimation of total bilirubin concentration was by performed on an Olympus AU 800 autoanalyser using the sulphanilic acid with surfactant reagent method.

Plasma volume changes were derived from changes in haemoglobin and packed cell volume. ${ }^{2}$ All results were corrected for changes in plasma volume with the exception of red cell parameters, haemoglobin and packed cell volume, and variables expressed as percentages.

Statistical significance of paired differences in means and standard deviations of the meta-

Table 3 Changes in haemoglobin, packed cell volume, red cell parameters and plasma volume

\begin{tabular}{lllll}
\hline Parameter & Pre-race & Day 4 & Day 11 & Post-race \\
\hline Haemoglobin $(\mathrm{g} / \mathrm{l})$ & $149.2(10.6)$ & $138.1(9.2)^{\star}$ & $134(16.4)^{\star}$ & $139.8(8.9)^{\star}$ \\
Packed cell volume & $0.43(0.03)$ & $0.40(0.03)^{\star}$ & $0.38(0.05)^{\star}$ & $0.40(0.03)^{\star}$ \\
Red cell count $\left(\times 10^{12} / 1\right)$ & $4.7(0.4)$ & $5.0(0.5)^{\star}$ & $4.9(0.6)$ & $4.9(0.6)$ \\
Mean cell volume (fl) & $91(4)$ & $90(4)^{\star}$ & $91(4)$ & $91.0(3)$ \\
Mean cell haemoglobin (pg) & $32(1)$ & $31(2)$ & $32(1)$ & $32(1)$ \\
Plasma volume (\% change) & & $13.4^{\star}(4.3)$ & $16.6^{\star}(11.6)$ & $12.6^{\star}(9.8)$ \\
\hline${ }^{\star} \mathrm{p}<0.05$ v pre-race value. & & & &
\end{tabular}

Table 4 Changes in total and differential white cell counts

\begin{tabular}{lllll}
\hline Parameter & Pre-race & Day 4 & Day 11 & Post-race \\
\hline White cell count $\times 10^{9} / 1$ & $5.5(0.7)$ & $10.2^{\star}(2.8)$ & $10.1^{\star}(3.6)$ & $8.4^{\star}(1.9)$ \\
Neutrophils (\%) & $58(12)$ & $70^{\star}(8)$ & $77^{\star}(10)$ & $66^{\star}+(7)$ \\
Lymphocytes (\%) & $30(10)$ & $19^{\star}(7)$ & $16^{\star}(7)$ & $21^{\star}+(6)$ \\
Monocytes (\%) & $9(2)$ & $8(2)$ & $5^{\star}(2)$ & $7^{\star}(1)$ \\
Eosinophils (\%) & $2(1)$ & $2(1)$ & $2(1)$ & $3(1)$ \\
Basophils $(\%)$ & $1(0)$ & $1(1)$ & $1(1)$ & $2^{\star}(1)$ \\
Neutrophils $\times 10^{9} / 1$ & $3.2(0.6)$ & $7.2^{\star}(2.6)$ & $7.9^{\star}(3.3)$ & $5.0^{\star}+(2.0)$ \\
Lymphocytes $\times 10^{9} / 1$ & $1.7(0.7)$ & $1.9^{\star}+(0.6)$ & $1.5(0.7)$ & $1.9(0.4)$ \\
Monocytes $\times 10^{9} / 1$ & $0.5(0.1)$ & $0.8^{\star}(0.2)$ & $0.4(0.2)$ & $0.6(0.2)$ \\
Eosinophils $\times 10^{9} / 1$ & $0.13(0.08)$ & $0.16(0.1)$ & $0.25^{\star}(0.15)$ & $0.31^{\star}(0.19)$ \\
Basophils $\times 10^{9} / 1$ & $0.05(0.02)$ & $0.20(0.27)$ & $0.06(0.07)$ & $0.017^{\star}(0.07)$ \\
\hline
\end{tabular}

${ }^{\star} \mathrm{p}<0.05 v$ pre-race value.

$+\mathrm{p}<0.05 v$ day 11 value. bolic alterations over time were calculated by Student's $t$ test. The level of significance was set at $\mathrm{p}<0.05$.

\section{Results}

Table 1 summarises the characteristics of the subjects taking part in this study and table 2 gives the performance data for each of the runners.

Packed cell volume, haemoglobin, and red cell count decreased significantly below prerace values at day 4 , and did not change further on days 11 and 17. However, when the absolute red cell count was corrected for plasma volume expansion an increase was found on day 4 (table 3).

Mean cell volume decreased significantly from pre-race values at day 4 , increased and was not significantly different from pre-race at day 11 , and remained unchanged until the end of the event (table 3).

The white blood cell count increased significantly between the start of the race and day 4 and remained unchanged until the end of the run. The percentage and absolute number of neutrophils was increased on days 4 and 11 then decreased between day 11 and race end, the final value remaining significantly higher than that pre-race. The percentage of lymphocytes was decreased on days 4 and 11 then increased between day 11 and race end, the final value remaining significantly lower than that pre-race. Absolute numbers of lymphocytes increased between pre-race and day 4 , decreased significantly between days 4 and 11 , and then remained depressed until the conclusion of the run when the value was not significantly different from the pre-race value (table 4).

The percentage of monocytes was decreased on days 11 and post-race, but the absolute number of monocytes was increased above pre-race values on day 4 . Although no change occurred in the percentage of eosinophils, the absolute number was increased on day 11 and at the end of the race. Both the percentage and absolute number of basophils were increased at the end of the race (table 4).

Mean values for white blood cell count remained normal, but a relative neutrophilia was found on day 11, an absolute neutrophilia not occurring at any time. Despite decreases in absolute numbers of lymphocytes in the middle stages of the run they remained within the normal range. Absolute numbers of monocytes, eosinophils, and basophils remained within normal limits at all times.

The platelet count increased significantly between the start of the race and day 4 and again between days 4 and 11, and no further rise was found at the end of the event. The mean platelet count remained within the normal range at all data points.

Both the percentage and absolute numbers of reticulocytes were increased on days 4,11 , and at the end of the event. All means remained within the normal range (table 5).

Table 6 shows the changes in parameters related to iron metabolism and haemolysis. 
Table 5 Changes in platelets and reticulocytes

\begin{tabular}{lllll}
\hline Parameter & Pre-race & Day 4 & Day 11 & Post-race \\
\hline Platelets $\times 10^{9} / 1$ & $254(51)$ & $314^{\star}(54)$ & $391^{\star}(73)$ & $440^{\star}(125)$ \\
Reticulocytes $(\%)$ & $0.8(0.2)$ & $1.0^{\star}(0.5)$ & $1.3^{\star}(0.6)$ & $1.3^{\star}(0.6)$ \\
Reticulocytes $\times 10^{9} / 1$ & $38(9)$ & $50^{\star}(23)$ & $63^{\star}(26)$ & $64^{\star}(25)$ \\
\hline
\end{tabular}

${ }^{\star} \mathrm{p}<0.05 v$ pre-race value.

Table 6 Changes in parameters related to iron metabolism and haemolysis

\begin{tabular}{lllll}
\hline Parameter & Pre-race & Day 4 & Day 11 & Post-race \\
\hline Iron $(\mu \mathrm{mol} / \mathrm{l})$ & $21(3)$ & $14^{\star}(5)$ & $12^{\star}(2)$ & $16^{\star}(5)$ \\
Ferritin $(\mu \mathrm{g} / \mathrm{l})$ & $109(76)$ & $204^{\star}(102)$ & $170^{\star}(86)$ & $150^{\star}(77)$ \\
TIBC $(\mu \mathrm{mol} / \mathrm{l}) \dagger$ & $72(7)$ & $69(12)$ & $66^{\star}(11)$ & $76(10)$ \\
Transferrin saturation $(\%)$ & $30(5)$ & $20^{\star}(5)$ & $19^{\star}(2)$ & $21^{\star}(7)$ \\
Haptoglobin $(\mathrm{g} / \mathrm{l})$ & $1.81(0.73)$ & $3.41^{\star}(0.89)$ & $3.90^{\star}(0.64)$ & $4.12^{\star}(1.19)$ \\
Bilirubin $(\mu \mathrm{mol} / \mathrm{l})$ & $13(7)$ & $22^{\star}(17)$ & $10(5)$ & $10(3)$ \\
\hline
\end{tabular}

${ }^{\star} \mathrm{p}<0.05 v$ pre-race value.

+ TIBC $=$ total iron binding capacity.

Serum iron concentration was decreased below pre-race values on days 4,11 , and at the end of the race. Mean values remained within the normal range and on day 11 approached the lower limit of normal.

Serum ferritin concentration was increased compared with its pre-race value on days 4,11 , and at the end of the run. Mean values remained within the normal range.

Transferrin saturation decreased between pre-race and day 4, remained unchanged between days 4 and 11 , and 11 and race end, at which time it remained significantly lower than its pre-race value. Mean values remained within the normal range but approached the lower limit of normal.

Total iron binding capacity was significantly different from pre-race values on day 11 only. Its mean value was above the normal range before the run but returned to the normal range during the race and then was again above the normal range at the end of the event.

Haptoglobin concentration increased between pre-race and day 4 and remained above pre-race values at both day 11 and at the end of the event. On days 4,11 , and at the end of the event mean values were above the normal range.

Bilirubin concentration increased between pre-race and day 4, when it was raised above the normal range, returning to a level not significantly different from pre-race levels on day 11 and at the end of the event.

\section{Discussion}

Very little has been reported on the biochemical and haematological changes occurring during and after very long ultramarathons, and in some cases the available data have been derived from staged rather than continuous events. This study provides baseline data for further research into events that test the outer limits of endurance. Caution needs to be exercised in the interpretation of the end of race data in this study as it represents a number of end points, which include completion of 1600 $\mathrm{km}, 16$ days of running, and early retirement from the race. However, it should be noted that each of four runners completed $1600 \mathrm{~km}$, three of the others finished on the 16th day, and the runner who finished on day 12 had completed $1364 \mathrm{~km}$.
HAEMOGLOBIN AND PACKED CELL VOLUME Packed cell volume, haemoglobin, and red cell count decreased significantly below pre-race values at day 4 , and did not change further on days 11 and 17 . However, when the absolute red cell count was corrected for plasma volume expansion an increase was found on day 4.

This set of findings, when not corrected for change in plasma volume, is the same as that of Dressendorfer, who found that all three variables were decreased on day 2, reached close to their minimum on day 5 , and remained depressed until day 20 of an event in which runners covered a total of 312 miles. $^{3}$

Significant variability in responses in haemoglobin and packed cell volume is not unusual in ultradistance events. ${ }^{14-8}$ In our study only one runner had haemoglobin and packed cell volume levels below the normal range, and this was due to an episode of gastrointestinal bleeding thought to be related to ingestion of non-steroidal antiinflammatory drugs.

Decreases in both haemoglobin and packed cell volume may be expected in relation to increased plasma volume during prolonged exercise, but the possibility of both intravascular haemolysis from mechanical trauma, osmotic and oxidative damage to erythrocytes, and overt or occult blood loss should also be considered. ${ }^{9}$ Calculated mean plasma volume changes in this study were $13.4 \%$ on day 4 , $16.6 \%$ on day 11 , and $12.6 \%$ at the conclusion of the run.

So called "sports anaemia" is a commonly encountered chronic dilutional state in endurance trained athletes. ${ }^{10}$ It is characterised by relatively low values for haemoglobin, packed cell volume, and red cell count. Despite significant training distances "sports anaemia" was not shown in this group of runners, all of whom had pre-race values for these variables well above the lower limits of normal.

\section{RED CELL PARAMETERS}

Mean cell volume has been reported to be increased and mean cell haemoglobin concentration decreased after a marathon run, ${ }^{11}$ but no change was found in either variable after a $100 \mathrm{~km}$ run, ${ }^{12} 160 \mathrm{~km}$ run, ${ }^{7}$ and during or after a 20 day, 312 mile run. ${ }^{3}$ Mean cell haemoglobin concentration was found to be decreased, however, in a group who ran $1000 \mathrm{~km}$ in 20 days. ${ }^{1}$ The small but significant decrease in mean cell volume found in this study is unlikely to indicate iron deficiency as the haematological status of the runners was normal before the event, the mean cell volume remained in the normal range, and the development of microcytosis in iron deficient states can take several weeks to develop. ${ }^{14}$ It is unusual that a decrease in mean cell volume occurred at a time when reticulocytosis was also present and, possibly, this small change may not be truly significant if the normal variability of measurement of the analyser is taken into account. 
PLATELETS

Increases in platelets have been reported after marathon running, ${ }^{11}$ but no change occurred after an ultratriathlon $(7.5 \mathrm{~km}$ swim, $360 \mathrm{~km}$ cycle, and $85 \mathrm{~km}$ run). ${ }^{15}$ To our knowledge platelet count has not been previously measured in an event of this duration. The significance of the increase is unclear.

WHITE CELL COUNT

Increases in white cell count have been documented after the standard marathon, ${ }^{11}$ $160 \mathrm{~km}$ runs, ${ }^{16}$ and 24 hour runs. ${ }^{5}$ No change was found in white cell count after one $160 \mathrm{~km}$ run, ${ }^{7}$ but this may be explained by delayed sampling, which occurred 48 hours after the event. Neutrophilia occurring early in exercise is related to catecholamine induced demargination of neutrophils, but a delayed increase is mediated by cortisol induced release of neutrophils from bone marrow or mobilisation due to chemotactic factors released from damaged tissues. ${ }^{17}$ Both these factors are operational during ultramarathon running.

Monocytes are known to increase two- to threefold during exercise, the rapidity of this increase indicating mobilisation rather than increased production. ${ }^{18}$ They produce interleukin-1, which is an important mediator of the acute phase response. ${ }^{19}$ This is consistent with the findings of this study.

\section{RETICULOCYTES}

Both percentage and absolute numbers of reticulocytes were increased on days 4,11 , and at the end of the event. All means remained within the normal range. No changes in reticulocytes in events of this duration have been reported, but no change in reticulocyte count was found after a $100 \mathrm{~km}$ run. ${ }^{13}$ The reticulocytosis has a number of possible causes, including gastrointestinal and urinary blood loss ${ }^{1}$ and haemolysis due to foot strike. The significant increase in bilirubin on day 4 may provide some evidence for a haemolytic state.

HAPTOGLOBIN

Haptoglobin is an acute phase protein ${ }^{20}$ and as prolonged exercise typically produces an acute phase response an increase during an event of this duration is not unexpected. Despite this, haptoglobin concentration has been found to be depressed after marathon running, ${ }^{11} 160 \mathrm{~km}$ ultramarathons, ${ }^{16}$ and a 24 hour run. ${ }^{5}$ This is thought to be related to intravascular haemolysis ${ }^{21}$ associated with mechanical trauma at foot strike. The rise shown during our study does not discount the possibility of intravascular haemolysis but probably indicates the intensity of the acute phase reaction consequent upon muscle damage and acute inflammatory processes occurring in other musculoskeletal tissues. Periods of intense training, which can be likened to strenuous daily running, also cause prolonged increase of both haptoglobin and serum ferritin concentrations owing to maintenance of a chronic acute phase response; concern has been expressed that this could mask early iron deficiency in athletes. ${ }^{22}$
BILIRUBIN

Bilirubin concentration increased between pre-race and day 4, when it was raised above the normal range, returning to a level not significantly different from its pre-race value on day 11 and at the end of the event. After a 160 $\mathrm{km}$ run a significant increase in bilirubin concentration was found, which when broken down into direct and indirect types suggested intravascular haemolysis. ${ }^{8}$ No change was found after a $1000 \mathrm{~km}, 20$ day run, but a significant increase was seen on day 3 , a similar pattern to that of the current study. ${ }^{1}$ Although only total bilirubin was measured in that study, if taken in conjunction with low haptoglobin concentrations on day 3 of the $1000 \mathrm{~km}$ run, it is possible that this indicates maximum haemolysis occurring during the early stage of the event. This is consistent with the hypothesis that foot strike is the causative factor of haemolysis as runners in ultramarathons typically adopt a shuffling gait as the event progresses, which is likely to be accompanied by a lower force of foot strike and, therefore, potentially less damage to red blood cells. Another possible explanation for maximum haemolysis in the early stage of the event is that as older red cells are more fragile, those most vulnerable may be damaged early, and once these are removed from the circulation a steady state is reached. ${ }^{1}$

SERUM IRON

Serum iron concentration was decreased below pre-race values on days 4,11 , and at the end of the race. Mean values remained within the normal range. Decreased serum iron concentration is consistent with an acute phase response, ${ }^{20}$ and this response has been shown after $160 \mathrm{~km}$ ultramarathons ${ }^{16}$ and 24 hour runs. ${ }^{5}$ Serum iron has been found to be raised on day 3 of a $1000 \mathrm{~km}$ run, ${ }^{1}$ but in that event runners only ran $50 \mathrm{~km}$ a day and then rested for periods of presumably greater than 16 hours. In that event a decrease from the pre-race value was seen at day 6 . The mechanism of the fall in serum iron is controversial, but an increase in ferritin synthesis in the reticuloendothelial cells and diversion of iron to that store accompanied by inhibition of iron release, similar to that occurring in the anaemia associated with chronic disease, is a likely explanation.

\section{TOTAL IRON BINDING CAPACITY}

Total iron binding capacity was significantly different from pre-race values on day 11 only. Its mean value was above the normal range before the run, returned to the normal range during the race, and then was again above the normal range at the end of the event. Total iron binding capacity has rarely been measured during this type of event but it was found to be unchanged after a $160 \mathrm{~km}$ ultramarathon. ${ }^{16}$

\section{TRANSFERRIN SATURATION}

Transferrin saturation decreased between prerace and day 4, remained unchanged between days 4 and 11 , and 11 and race end, at which time it remained significantly lower than 
pre-race values. Mean values remained within the normal range but approached the lower limit of normal. No change but wide variation was seen after a $1000 \mathrm{~km}$ stage run, ${ }^{1}$ and a reduction has been documented after a $160 \mathrm{~km}$ triathlon. ${ }^{16} \mathrm{~A}$ reduction in transferrin saturation typically occurs in the anaemia associated with chronic disease and a short term acute phase response leading to low iron availability is the likely explanation for the reduction found in this study.

SERUM FERRITIN

Serum ferritin concentration was increased compared with pre-race values on days 4,11 , and at the end of the run. Mean values remained within the normal range. This is similar to the study of Seiler, who found an increase during the first three days, followed by a slight decrease without reaching initial values during a $1000 \mathrm{~km}$ run. ${ }^{1}$ This increase is consistent with an acute phase response. Serum ferritin concentration is often used as a single variable for the diagnosis of deficient iron stores in athletes. The acute phase response of this protein should be recalled in this situation, and therefore determination of serum ferritin should be performed at a time remote from strenuous exercise of long duration and ideally accompanied by other iron studies, including determination of percentage transferrin saturation, serum iron, and total iron binding capacity.

\section{Conclusion}

This study has documented haematological and iron related parameters during a continuous $1600 \mathrm{~km}$ foot race. Participation was shown to have no significant negative effect on the haematological system, but study of more subtle indicators of red cell production, including reticulocyte variables, may indicate otherwise. There seem to be a number of differences in responses between staged and continuous races over similar long distances. These may be related to the group studied, the total distance covered, intensity of exercise, differences in the acute phase response to musculoskeletal tissue damage, or failure to consider the effects of plasma volume changes.

Analysis of pre-race samples indicates that in this group of relatively old, experienced runners, training an average of almost $200 \mathrm{~km}$ per week has no detrimental effect on haematological or iron related parameters as all of these were within the normal range of the general population. Haemodilution has been shown to occur in already well trained runners, and changes in haemoglobin, packed cell volume (whilst related to plasma volume change), serum iron concentration, percentage transferrin saturation, total iron binding capacity, and ferritin are similar to those found in the anaemia of chronic disease. They do not, however, indicate the presence of such anaemia but reflect the acute phase response common to a variety of chronic illnesses and strenuous endurance exercise of long duration. Athletes can adapt to these changes and they are not deleterious to them. An awareness of the acute phase response and changes in plasma volume is important when assessing the significance of a wide range of haematological and biochemical parameters in athletes.

1 Seiler D, Nagel D, Franz H, et al. Effects of long distance running on iron metabolism and haematological parameters. Int $\mathcal{F}$ Sports Med 1989;10:357-62.

2 Dill DB, Costill DL. Calculation of percentage changes in volumes of blood, plasma and red cells in dehydration. $\mathcal{F}$ Appl Physiol 1974;37:247-8.

3 Dressendorfer RH, Wade CE, Amsterdam EA. Development of pseudoanaemia in marathon runners during a 20 day road race. $\mathcal{F} A M A$ 1981;246:1215-18.

4 Fellman N, Sagno IM, Bedu M, et al. Enzymatic and hormonal responses following a 24 hour endurance run and a 10 hour triathlon race. Eur $f$ Appl Physiol 1988;57:545-53.

5 Nagel D, Seiler D, Franz H. Biochemical, haematological and endocrinological parameters during repeated intense short-term running in comparison to ultra-long distance running. Int $\mathcal{F}$ Sports Med 1992;13:337-43.

6 Fellmann N, Bedu M, Giry J, et al. Hormonal, fluid, and electrolyte changes during a $72 \mathrm{hr}$ recovery from a $24 \mathrm{hr}$ electrolyte changes during a $72 \mathrm{hr}$ recovery from

7 Dickson DN, Wilkinson RL, Noakes TD. Effects of ultra-marathon training and racing on haematologic parameters and serum ferritin levels in well-trained athletes. Int $\mathcal{F}$ Sports Med 1982;3:111-17.

8 Noakes TD, Carter JW. Biochemical parameters in athletes before and after having run 160 kilometers. S Afr Med $\mathcal{F}$ 1976;50:1562-6.

9 Smith J. Exercise, training and red blood cell turnover. Sports Med 1995;19:9-31.

10 Eichner ER. The anaemias of athletes. Physician and Sportsmedicine 1986;14:122-30.

11 Davidson RJL, Robertson JD, Galea G, et al. Haematological changes associated with marathon running. Int $\mathcal{F}$ Sports Med 1987;8:19-25.

12 Rama R, Ibanez J, Riera M, et al. Haematological, electrolyte and biochemical alterations after a $100 \mathrm{~km}$ run Can f Appl Physiol 1994;19:411-20.

13 Staubli M, Roessler B. The mean red cell volume in distance runners. Eur f Appl Physiol 1986;55:49-53.

14 Clarkson DR, Moore EM. Reticulocyte size in nutritional anaemias. Blood 1976;48:669-77.

15 Lehmann M, Huonker M, Dimeo L. Serum amino acid concentrations in nine athletes before and after the 1993 Colmar ultratriathlon. Int F Sports Med 1995;16:155-9.

16 Taylor C, Rogers G, Goodman C, et al. Hematologic, iron related and acute-phase protein responses to sustained strenuous exercise. F Appl Physiol 1987;62:464-9.

17 Pyne D. Regulation of neutrophil function during exercise. Sports Med 1994;17:245-58.

18 Bousquet J, Chanez P, Mercier J, et al. Monocytes, exercise and the inflammatory response. Exerciese Immunology Review 1996;2:35-44.

19 Osterud B, Olsen JO, Wilsgard L. Effect of strenuous exercise on blood monocytes and their relation to coagulation. Med Sci Sports Exerc 1989;21:374-8.

20 Jupe D. The acute phase response and laboratory testing. Aust Fam Physician 1996;25:324-9.

21 Deitrick RW. Intravascular haemolysis in the recreational runner. Br f Sports Med 1991;25:183-7.

22 Witte DL. Can serum ferritin be effectively interpreted in the presence of the acute phase response? Clinical Chemistry 1991;37:484-5. 


\section{Commentary}

Some research takes its subjects to such extremes that it provides unique opportunities to study the limits of human endurance and thereby to test hypotheses generated from less demanding work.

This paper represents a remarkable achievement by all the athletes taking part and provides an opportunity to determine whether the factors contributing to athletes' anaemia exert a greater effect after an exceptionally prolonged test of endurance. The results indicate that the well established prime cause-dilutional pseudo-anaemia - remains the main factor even at the limits of endurance. Although haemolysis from foot strike can cause iron loss through haemoglobinuria in susceptible subjects, haemolysis as measured by haptoglobin concentrations did not contribute to the "anaemia" in these experienced runners. The very slight increase in reticulocytes suggests that a mild degree of compensated haemolysis might be occurring but certainly insufficient to contribute to the anaemia. Experienced ultramarathon runners should have an efficient running style without excessive foot strike, which has been identified as a cause of haemolysis.

The iron studies and other parameters show that iron continues to be re-used as normal allowing for the acute phase response that can accompany severe physical stress and can also be the result of muscle damage.

E J WATTS

\section{Barbados to the BASM course, via the London marathon!}

"You will never make it!" My father's words rang in my ears as I sped up the motorway. The logistics of running in the London marathon on the morning of Sunday 13 April 1997 and then reaching Lilleshall Hall National Sports Centre in time for the start of the BASM introductory course (first lecture $730 \mathrm{pm}$ ) meant a rapid escape from the marathon finish!

I am an English GP, trained at the Middlesex Hospital, who has been working in Barbados since 1982, having fallen in love with the island on my medical student elective in 1980 .

The easy tropical climate, sports orientated friends, and body conscious society encouraged me to start running about eight years ago, although I had always enjoyed aerobics. I had completed the London marathon in 1994 and 1996, so thought that a third time would round it off nicely not realising the eventual clash of dates with the BASM course.

I flew back to England on Tuesday 8 April, hoping for (relatively) warm temperatures; memories of a freezing start in my bin liner at the 1994 marathon still haunt me! Fortunately, the weather was mild on Sunday 13th when I travelled to the Blackheath start on the sardine-like free train from Waterloo East. I soaked up the atmosphere as thousands of runners milled about, queued in the interminably long toilet lines, and rubbed copious amounts of liniment into vital anatomical places!

A long standing left plantar fasciitis, causing my heel to feel as if a red hot poker was being stuck into it (which gave me increased sympathy for similarly afflicted patients!) reduced the likelihood of a good time. A recently fitted orthotic unfortunately caused a huge blister on my inner left foot which made the last six miles a painful experience (although much kudos should go to those who provided me with excellent service at Headley Court). I ended up running the last mile hand in hand with a "clown" from Epsom, who was also suffering!

Maybe because I was attached to a tall sweaty man in makeup and wig, my two sisters who were to meet me failed to spot me crossing the finish line, causing a 45 minute delay at the "Repatriation Point" - a chaotic area, many painful yards from the finish, where runners on mobile phones try to locate their relatives!

Eventually we met up, made it through London's underground system (so many steps to walk down!) to the car and then to Lilleshall.

I walked into the lecture room, to gruesome sports injury slides on the screen and a round of applause-I was still wearing my running kit, medal, and tracksuit! 